\title{
Research on Pharmaceutical School Pharmaceutical Talents Training Mode under Double High Background
}

\author{
Lijuan Cheng \\ Yichun Vocational Technology College, Yichun 336000, China \\ 20175490@qq.com
}

\begin{abstract}
The vocal school education is an important part of China's higher education, which trains technical and applied professionals for the front line of production, management and service. With the continuous development of China's economy and the remarkable improvement of people's living standards, China has higher and higher requirements for personnel training. However, there are still some problems in the development of vocal school and the mode of personnel training in China. It is of great practical significance and far-reaching historical significance to train high-quality applied talents in pharmacy for realizing the modernization of China's pharmaceutical industry, revitalizing the pharmaceutical economy and improving the medical and health level of the people. This paper focuses on the lack of pharmaceutical talents training mode in vocal school under the background of double high school, and puts forward feasible suggestions. With a view to improving the current situation of pharmaceutical talents training in Chinese vocal school, making some contributions to the vigorous development of Chinese medical undertakings and laying a foundation for improving the comprehensive quality of pharmaceutical professionals in Chinese vocal school.
\end{abstract}

Keywords: Pharmaceutical Talents; Training Mode; Comprehensive Quality.

\section{Introduction}

Vocational school education is an important part of China's higher education. It trains technical and applied professionals for the front line of production, management and service, undertakes the responsibility of providing intellectual support for the transformation of high and new technology and the upgrading of traditional industries, and cultivating workers' employability and entrepreneurial ability [1]. Today, with the inverted pyramid structure of China's employed personnel, the Ministry of education requires to vigorously strengthen higher vocational education, and our university will complete the transformation from secondary vocational education to higher vocational education in the next few years [2]. The cultivation of pharmaceutical professionals is not only the fundamental source of demand for talents in China's medical undertakings, but also the talent supply of Chinese medical institutions and other relevant units. It shoulders the important task of providing talents for China [3]. However, from the current training mode and teaching means of pharmaceutical professionals in Chinese vocational school, it is not ideal, and there are some problems and deficiencies. Cultivating high-quality pharmaceutical high-tech applied talents who adapt to the development of the industry has important practical and far-reaching historical significance for realizing the modernization of China's medical and pharmaceutical industry, revitalizing the pharmaceutical economy and improving the medical and health level of the people [4].

From clinical drug application specialty to pharmacy specialty, it is not only the change of specialty name, but also the change of training objectives and employment direction. This change puts forward higher requirements for the professional quality of graduates, increases the difficulty and competitiveness of employment, and puts forward new challenges to the teaching and practice of pharmacy [5]. The general training goal of vocational school students is to cultivate applied talents who master professional skills facing the needs of society and market. Pharmaceutical School Students Majoring in pharmacy are mainly employed in pharmaceutical factories, pharmacies, pharmaceutical companies, hospital pharmacies, etc. With the development of economy, society and pharmacy, the traditional concept of pharmacy, the functions and working mode of pharmaceutical practitioners are changing, while the development of pharmaceutical education in vocational school lags behind [6]. Therefore, pharmaceutical education in vocational school is faced with the realistic 
and necessary problem of how to cultivate talents and what kind of talents to cultivate [7]. In order to meet the needs of social development, promote the rapid development of China's pharmaceutical industry, improve the training quality of pharmaceutical professionals and cultivate high-quality technical and skilled pharmaceutical talents, this paper carries out relevant research on the improvement of the training quality of pharmaceutical professionals in combination with the current industrial development reality and economic situation. In view of the lack of pharmaceutical talent training mode of vocational school, this paper puts forward feasible suggestions, in order to improve the current situation of pharmaceutical talent training of vocational school in China, make a certain contribution to the vigorous development of Chinese medical cause, and lay a foundation for improving the comprehensive quality of pharmaceutical professionals of vocational school in China.

\section{Significance and Current Situation of Pharmaceutical Professional Personnel Training in Vocational School}

Pharmaceutical education in vocal school is the foundation of personnel training, which combines theoretical knowledge and practical application of pharmacy. Its main goal is to promote the development of Chinese pharmaceutical industry and contribute to the talent demand of Chinese medical cause. With the sustained development of China's economy and the continuous improvement of people's medical requirements, the current pharmaceutical vocational education has become increasingly difficult to meet the needs of the society. The curriculum and knowledge structure of pharmaceutical education in vocal school are not suitable for the needs of the society, and the knowledge update is slow, which cannot keep up with the development of modern pharmacy and the requirements of society for pharmacy. In the process of teaching, the teaching content is seriously inconsistent with the needs of modern society, which leads to the content that students have learned in school, which cannot be applied to social teaching in future practical work, resulting in the lack of teaching [8]. Of course, the problems pointed out here are only the tip of the iceberg. When faced with these situations, educational institutions should speed up the reform and deepening of pharmaceutical education in vocal school, and fundamentally improve the overall development of China's pharmaceutical industry.

Talent training mode is a key issue in the reform, which mainly includes training objectives, curriculum, teaching design, training approaches, construction of teachers and other elements. Pharmaceutical education in vocal school should optimize the combination of the above factors, and seek an optimal talent training mode that meets the current needs of China's medical and health development. At present, the teachers of pharmacy major in vocal school are mostly graduates from undergraduate colleges, with solid theoretical knowledge and scientific research ability, but the production practice experience of enterprises is insufficient, which is limited to theory and lacks practical experience [9]. However, some technical backbone teachers imported from enterprises have first-line production experience and strong practical ability, but they are also separated from actual production posts, and cannot understand new technologies and processes of enterprises and industries in time. With the continuous development of China's economy and the remarkable improvement of people's living standards, China's requirements for medical standards are constantly increasing. However, from the development of China's pharmaceutical vocational education, it can no longer meet the needs of China's current medical level.

Pharmaceutical major of vocal school mainly trains applied talents, and directly connects with enterprises after graduation, engaging in drug sales, experimental technology and other related work. With the rapid upgrading of pharmaceutical industry, the demand of enterprises for technical and skilled talents is constantly changing, which requires the graduates trained by schools not only to have enough professional knowledge reserves, but also to have the abilities of professional quality, practical operation, innovation, management and communication, etc. Therefore, the reform of pharmaceutical education in vocal school is an inevitable trend, and it is also an inevitable trend of pharmaceutical development in China in the future, showing a situation of sustainable development 
Volume 3 (2021)

for Chinese educational institutions. Then, from the perspective of personnel training, personnel training is the key to reform and the focus of reform. Therefore, it is necessary to reform and deepen the reform objectives, teaching contents, teaching links, teaching strategies, teaching design, training process, and teachers' strength, to improve the talent training mode for the development of Chinese medicine and health on the whole.

\section{Strategies of Cultivating Pharmaceutical Professionals in Vocational School}

\subsection{Curriculum of Pharmacy}

The construction of pharmaceutical professional training objectives in vocal school is aimed at the overall teaching plan and objectives of pharmaceutical major, and it is the overall plan and policy of teaching content reform and teaching strategy change, which has a positive effect on talent training in vocal school to a certain extent. The main difference between vocal school education and undergraduate education is to cultivate technical, applied and grass-roots talents, and to enable graduates to quickly adapt to the changes of new occupations and technologies in modern society. Therefore, the curriculum of vocal school education must closely follow the training objectives of vocational education, adapt to the job market and make it constantly improve. Figure 1 shows the information construction system structure of pharmaceutical professionals.

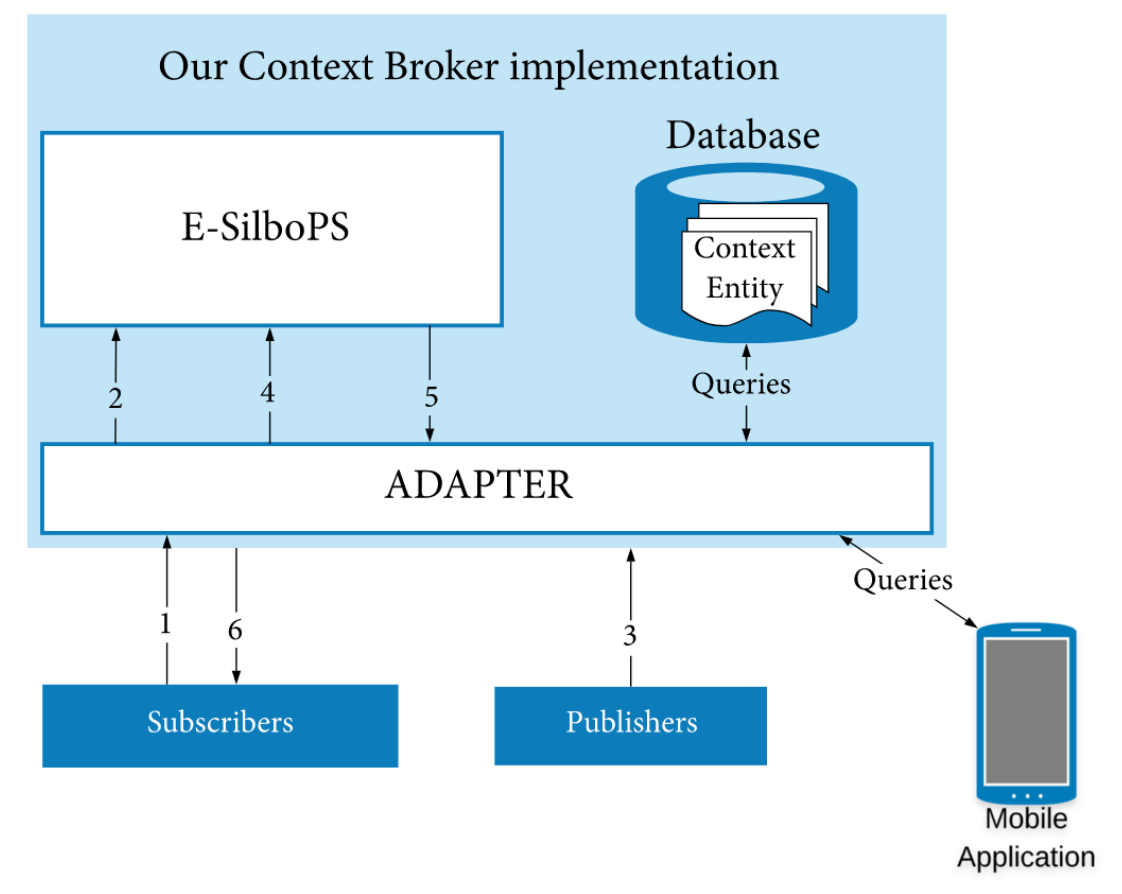

Figure 1. The system structure of the information construction of pharmacy professionals

In the process of setting teaching objectives for pharmaceutical professionals in vocal school, it is necessary to make clear the significance and strategies of constructing teaching objectives, to improve the practicality of teaching and the perfection of skills, and fundamentally improve the teaching effect. The fundamental difference between vocal school education and undergraduate teaching in colleges and universities lies in cultivating technical, applied and grass-roots talents, which can enable graduates to quickly adapt to the teaching of new occupations and new technologies in modern society, fundamentally improve the training of their teaching objectives, and enable students to adapt to the development of the market and constantly improve the market demand.

\subsection{Teaching Design of Pharmaceutical Specialty}

According to the training objectives of pharmaceutical professionals, we should reorganize the professional curriculum system and establish pharmaceutical professional groups based on 
professional basic courses, public basic courses, professional core courses and innovative entrepreneurship courses. Supported by professional basic courses and public basic courses, we pay attention to the cultivation of students' professional ability, cultural accomplishment, beneficial learning quality and sustainable development ability, and lay the foundation for students' high-quality employment and career development. Under the premise of the continuous development of society, there is an increasing demand for pharmaceutical talents in China, and the cultivation of pharmaceutical professionals in vocal school cannot be attached to the traditional training mode. We should constantly improve the construction of the teaching curriculum system, and fundamentally strengthen its humanistic quality [10]. The cultivation of professional skills and professional ethics can fundamentally strengthen the moral consciousness of medical professionals. Figure 2 shows the network structure system of talent information fusion management.

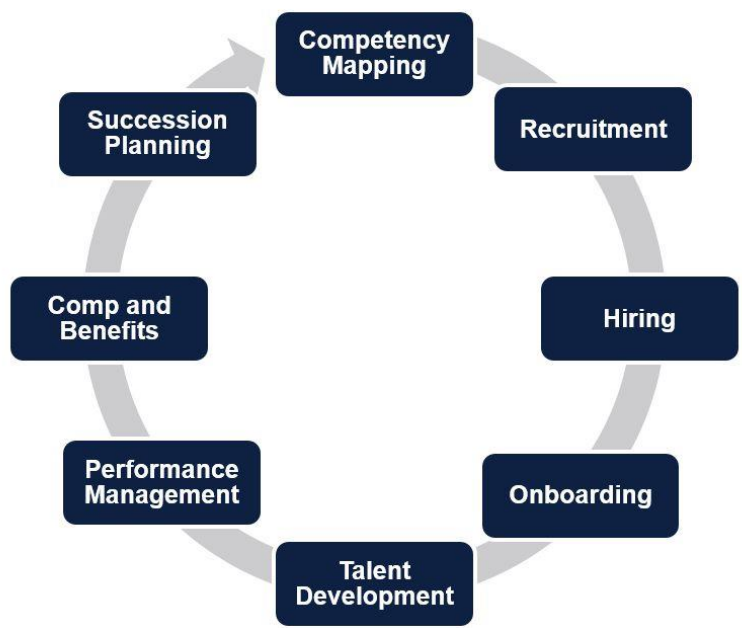

Figure 2. Talent information integration management network structure system

Professional teachers should actively go to enterprises, provide on-the-job training for their employees, and solve technical problems for enterprises. At the same time, they should also bring back the information of new processes and new equipment of enterprises to schools, and supplement and update the teaching contents, so that the teaching and scientific research of professional courses are always at the forefront of disciplines. Teaching design occupies an important position in the whole teaching, and the directness between the good and bad teaching design is related to students' learning interest and learning perception ability. Therefore, in the process of teaching, we should improve students' overall perception ability and learning achievements, and fundamentally improve their teaching strategies and results, to achieve the purpose of improving students' learning efficiency.

\section{Conclusion}

Reform the education mode of pharmaceutical talents training, and realize that the professional orientation is in line with social needs, and the training goal is in line with social needs. In the process of setting teaching objectives for pharmaceutical professionals in vocal school, it is necessary to make clear the significance and strategies of constructing teaching objectives, to improve the practicality of teaching and the perfection of skills, and fundamentally improve the teaching effect. For the cultivation of pharmaceutical professionals in vocal school, it is necessary to carry out continuous reform and innovation in teaching contents, teaching forms, teaching strategies and teachers. From the perspective of personnel training, personnel training is the key to the reform and the focus of the reform. Therefore, it is necessary to reform and deepen from the aspects of reform objectives, teaching contents, teaching links, teaching strategies, teaching design, training process and teachers' strength. According to the training objectives of pharmaceutical professionals, we should reorganize the professional curriculum system and establish pharmaceutical professional groups based on 
professional basic courses, public basic courses, professional core courses and innovative entrepreneurship courses. In the process of teaching, we should improve students' overall perception ability and learning achievements, and fundamentally improve their teaching strategies and results, to achieve the purpose of improving students' learning efficiency.

\section{References}

[1] Ruan Zhiyan, Shang Ling, Su Xinguo. Research on the cultivation of pharmacy professionals in higher vocational education under the background of supply-side reform[J]. Quality Education in West China, 2017, 3(021):189+191.

[2] Jiang Tao. The construction of a higher vocational Chinese medicine professional talent training model centered on traditional Chinese medicine skills[J]. Science Technology and Innovation, 2020, 165(21):1214.

[3] Lin Junior College. Higher vocational pharmacy personnel training in pharmacy services for social pharmacies [J]. China Health Care \& Nutrition, 2020, 030(008):276-277.

[4] Feng Chuanping, Ding Haixia, Peng Youling, et al. Research on the penetration of double creation awareness in pharmacy teaching in higher vocational colleges[J]. Health Vocational Education, 2017, 035 (013): 54-55.

[5] Wang Yanli, Gao Rongzhe, Peng Bo, et al. Innovative research on the training model of pharmacy talents in higher vocational colleges [J]. Education Teaching Forum, 2019, 413(19):75-76.

[6] Song Mei, Zheng Min, Zhao Gongbao, et al. Improving the training efficiency of higher vocational pharmacy service talents based on job competence[J]. Medical Higher Vocational Education and Modern Nursing, 2018, 1(05): 7-10.

[7] Li Junya, Li Jun. Discussion on the training strategy of pharmacy service talents in higher vocational colleges [J]. Health Vocational Education, 2016, 34(019): 15-16.

[8] Qin Hongbing, Xiong Cunquan, Jiang Liying, et al. Construction and implementation of pharmacy curriculum system in higher vocational colleges based on community pharmacy service personnel training [J]. Pharmaceutical Services and Research, 2016, 016(005):394-396.

[9] Liu Yongfei, Zhang Haihong, Shen Junbo, et al. Research on vocational pharmacy talent training for modern service industry [J]. Health Vocational Education, 2018, 036(015): 8-9.

[10] Yu Yanhua, Gao Zhiling, Zhang Chunfeng, et al. Research and practice of the school-enterprise cooperation talent training model for pharmacy in higher vocational colleges[J]. China Health Industry, 2016, 013(025): 35-37. 